\title{
Functional disability and post-traumatic stress disorder in survivors of mechanical ventilation: a cross-sectional study in Guangzhou, China
}

\author{
Ronghua $\mathrm{Li}^{1}$, Ying Zhou ${ }^{1}$, Xiaoqing Liu ${ }^{2}$, Jingye Huang ${ }^{2}$, Lihua Chen ${ }^{2}$, Huijin Zhang ${ }^{2}$, Yimin Li $^{2}$ \\ ${ }^{1}$ School of Nursing, Guangzhou Medical University, Guangzhou, China; ${ }^{2}$ Department of Critical Care Medicine, Guangzhou Institute of Respiratory \\ Health, The 1st Affiliated Hospital of Guangzhou Medical University, Guangzhou, China \\ Contributions: (I) Conception and design: R Li, Y Li, Y Zhou; (II) Administrative support: Y Li, X Liu; (III) Provision of study materials or patients: \\ Y Li, X Liu; (IV) Collection and assembly of data: R Li, J Huang, L Chen, H Zhang; (V) Data analysis and interpretation: R Li, Y Li, J Huang; (VI) \\ Manuscript writing: All authors; (VII) Final approval of manuscript: All authors. \\ Correspondence to: Yimin Li. Department of Critical Care Medicine, Guangzhou Institute of Respiratory Health, The 1st Affiliated Hospital of \\ Guangzhou Medical University, 151 Yan Jiang Road, Guangzhou, China. Email: dryiminli@vip.163.com.
}

Background: Critical illness is associated with cognitive, physical, and psychological impairments; however, evidence of the severity and frequency of impairments in Chinese survivors of mechanical ventilation in an intensive care unit (ICU) remains limited. Our aim was to investigate the incidence and severity of impairments in Chinese survivors of mechanical ventilation in ICU and to explore risk factors influencing specific impairments.

Methods: Patients discharged alive after mechanical ventilation in a large general ICU for $\geq 2$ days were enrolled in this single-center cross-sectional study. Survivors were evaluated using measures of functional disability (Activity of Daily Living Scale), and post-traumatic stress disorder (PTSD, The Impact of Event Scale-Revised) via telephone interview. Multivariable analysis was conducted.

Results: Data were obtained from 130 consenting survivors. At follow-up (mean: 19.64 months), among those in part-time or full-time employment prior to admission, only $45.1 \%$ had returned to work. Further, $29.2 \%$ of survivors had clear disabilities affecting daily living. Deficits in activities of daily living (ADL) were mainly characterized by impairment of instrumental ADL. Predictors of ADL in mechanically ventilated survivors included age, ICU admission diagnosis, and Acute Physiology And Chronic Health Evaluation II (APACHE II) score, which accounted for 33.5\% of total variance. Furthermore, $17.7 \%$ of participants had symptoms consistent with PTSD. ICU length of stay was the only predictor of PTSD, and accounted for $7.5 \%$ of total variance.

Conclusions: ICU survivors of mechanical ventilation in China face negative impacts on employment, and commonly have ADL impairment and PTSD. Age, ICU admission diagnosis, and APACHE II score were key factors influencing ADL, while ICU length of stay was the only factor affecting PTSD. These findings suggest that some survivors who have had certain exposures may warrant closer follow-up, and systematic interventions for these high-risk survivors should be developed in China.

Keywords: Mechanical ventilation; survivors; functional disability; post-traumatic stress disorder (PTSD)

Submitted Aug 07, 2020. Accepted for publication Jan 08, 2021.

doi: $10.21037 /$ jtd-20-2622

View this article at: http://dx.doi.org/10.21037/jtd-20-2622 


\section{Introduction}

As it is a populous country, China faces a continuously increasing demand for intensive care. According to an investigation in Guangdong province, by 2015 the number of intensive care units (ICUs) and ICU beds increased to 324 and 3,956, respectively (1). Meanwhile, due to developments in critical care medicine, survival outcomes have improved, and more than $80 \%$ of patients now survive ICU admission (2). For these survivors, critical illness and the experience in the ICU may be a gateway to post intensive care syndrome (PICS), which refers to new or worsening impairments in physical, cognitive, or mental health that arise after critical illness and persist beyond acute care hospitalization $(3,4)$, adversely affecting daily functioning and health-related quality of life.

A recent study of a large population of ICU survivors showed that they had a higher rate of new mental illness diagnoses in the year after discharge, compared patients following general hospitalization (5). In a prospective study of 1447 ICU survivors, Bastian and colleagues found that up to $31.6 \%$ of survivors presented with symptoms that indicated post-traumatic stress disorder (PTSD) (6). A recent review and meta-analysis found that PTSD symptoms may affect one in every five adult critical care survivors, with a high prevalence expected 12 months after discharge (7). Another 5-year longitudinal study of 196 survivors of acute respiratory distress syndrome (ARDS) showed that $23 \%$ of survivors reported symptoms of PTSD (8). Jackson et al. conducted a prospective, multicenter cohort study of 821 ICU survivors (2). The results showed that disabilities in basic activities of daily living (ADL) were present in $32 \%$ of patients at 3 months and $27 \%$ at 12 months, while disabilities in instrumental ADL were reported in $26 \%$ and $23 \%$ at 3 and 12 months, respectively (2). Earlier studies suggested that $<10 \%$ of ICU survivors who were mechanically ventilated for more than 4 days were able to live independently 1 year after hospital discharge (3,4,9-11).

Work is often considered as not only a necessity, but also an important factor in self-realization and satisfaction (12). The inability to return to work is common after critical illness due to PICS morbidities. A recent cohort study, which included 5762 ICU survivors, found that $68 \%$ had returned to work within 2 years of follow-up after hospital discharge (13). Similarly, in a longer-term follow-up of survivors of ARDS, only half had returned to work one year after discharge (14), and $77 \%$ at 5 years (15).

Despite the notion that PICS may be common and very important in ICU survivors, in particular survivors of mechanical ventilation, evidence related to PICS in Chinese survivors of critical illness remains limited. Additionally, the vast majority of current research into PICS was conducted in western developed countries. Given the differences between eastern and western cultures, PICS in mechanically ventilated survivors in developing countries requires further study. In addition, the ability to return to work after ICU discharge is an important indicator of the quality of life of survivors, and of great significance in evaluating the impact of critical illness and ICU treatment on the overall social economy. This is of particular interest in China, a developing country that needs a large number of workers.

In this study, we aimed to evaluate ADL, PTSD, and employment in survivors of mechanical ventilation after hospital discharge. We also aimed to identify factors influencing ADL and PTSD in survivors of mechanical ventilation.

We present the following article in accordance with the STROBE reporting checklist (available at http://dx.doi. org/10.21037/jtd-20-2622).

\section{Methods}

\section{Study design and participants}

In our single-center cross-sectional study, the convenience sampling was adopted. The sample size calculation was based on Hair and Anderson (16) recommendation of a minimum sample size of 5 subjects per item. The Impact of Event Scale-Revised (IES-R) had the maximum number of items (22 items) among all the scales used in this study. Therefore, the minimum sample size was 110 . Considering the possible loss of samples, all patients admitted to ICU in the $1^{\text {st }}$ Affiliated Hospital of Guangzhou Medicinal University during the 2016 calendar year were eligible to participate. Adults aged $\geq 18$ years who were admitted to the general ICU for at least $48 \mathrm{~h}$, had received at least $24 \mathrm{~h}$ of mechanical ventilation, and who were alive on hospital discharge were screened. Patients who had been in an ICU at any time in the 3 months before admission were excluded, as were those for whom telephone interview would be difficult, because of pre-existing substantive hearing impairment, dysarthria, or dementia, and those with pre-existing mental health illness, or significant deficits that precluded independent living, as reported by a healthcare proxy. We also excluded patients receiving palliative care and those who were in a coma until their discharge 
from hospital. The index presentation of data from our study included quality of life and patients' views on ICU rehabilitation clinics, but did not contain functional and mental outcomes (17).

The study was conducted in accordance with the Declaration of Helsinki (as revised in 2013). The study was approved by Ethical Committee of Guangzhou Medical University (No.: 201749) and informed consent was taken from all the patients.

\section{Procedure}

Data were collected from August 2017 to March 2018. First, eligible participants were identified via retrospective analysis of ICU patients' medical records. Then, we contacted potential participants by telephone, explained the purpose of the study, and ensured them of the confidentiality of their information. After obtaining consent from participants, questionnaires, covering employment, ADL, and PTSD, were conducted by telephone interview. Each patient was interviewed once. Socio-demographic and clinical data were obtained from electronic medical records.

To reduce bias, the same investigator conducted all interviews, using a pre-scripted question sequence. Exact items were read to each participant, and then they selected response options themselves. When participants had questions about the contents of the questionnaire, the answers were explained to them. If more than half of the questionnaire was not collected, due to a participant suspending the interview before completion, the corresponding data were eliminated. In cases of nonresponse, a second call was considered after several days. Subjects were considered lost if they could not be reached after three calls.

\section{Data collection}

Data on age, sex, education level, and other sociodemographic factors, including employment, were collected. Clinical data, collected based on participants' medical records on first admission to the ICU of the surveyed hospital in 2016, included admission diagnosis, Acute Physiology And Chronic health Evaluation II score (APACHE II) (18) (first rating within $24 \mathrm{~h}$ after ICU admission), length of mechanical ventilation (days), ICU length of stay (days), and hospital length of stay (days).

Functional disability was assessed according to score on the 14-item Activity of Daily Living Scale (ADL scale) (19), and PTSD evaluated according to score on the 22-item Impact of Event Scale-Revised (IES-R) (20).

The ADL scale is a four-point scale, comprising the Physical Self-maintenance Scale (PSMS) and Instrumental Activity of Daily Living Scale (IADL). PSMS includes using the toilet, feeding, dressing, grooming, physical ambulation, and bathing, while IADL includes using the telephone, shopping, preparing food, housekeeping, doing laundry, using transportation, handling medications, and handling finances (19). Total scores were in the range 14-56, with higher scores indicating more obvious impairment of ADL. For each item, 1 was rated as normal and 2-4 as impaired. If $\geq 2$ items scored $\geq 3$ points, or the total ADL scale score was $\geq 22$ points, it was considered obvious functional disability. For PSMS, a score of $\geq 2$ in at least one of the six items indicated impaired physical self-maintenance. The criteria for IADL were similar to those for PSMS.

IES-R is an instrument commonly used to assess PTSD symptoms in survivors of ICU (20), with higher scores indicating more symptoms of PTSD. In this study, a cut-off point of 35 (range, $0-88$ ) was used (21).

\section{Statistical analysis}

Data were exported to Epidata 3.1 and IBM SPSS v25.0 for analyses. Continuous variables were assessed for normality, with subsequent descriptive statistics presented as mean \pm standard deviation or median (P25-P75). Descriptive statistics of discrete variables are presented as $\mathrm{n}(\%)$. The chi-square test (or exact probability method) was used for comparisons between different groups. To identify factors associated with ADL and PTSD, univariable analysis (independent sample rank-sum tests (Kruskal-Wallis H), Spearman's rank correlation coefficient) was applied, with subsequent multiple linear regression analysis. Individual missing values were replaced by averages.

\section{Results}

\section{Participant characteristics}

A total of 248 patients were screened, according to the inclusion and exclusion criteria. Among these, 130 patients $(52.4 \%)$ were followed up successfully (Figure 1$)$. The characteristics of patients with follow-up were similar to those of patients without follow-up, except for age, admission diagnoses, and ICU length of stay (Table 1). The mean time from ICU discharge to follow-up day was 


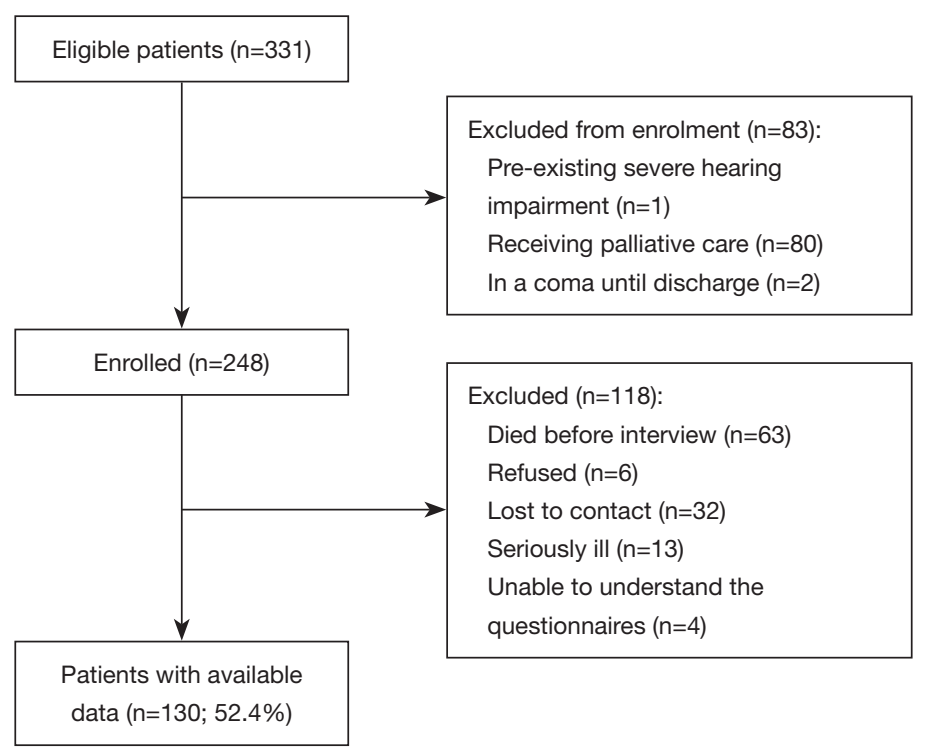

Figure 1 Study flow diagram.

$19.64 \pm 3.20$ months.

\section{Employment}

Approximately one quarter (25.4\%) of participants reported themselves as having full or part-time jobs, compared with $32.3 \%$ pre-admission. A further $18.5 \%$ were unemployed, compared with $6.9 \%$ pre-admission (Figure 2). Among 51 participants reported having jobs pre-admission, $45.1 \%$ returned to their previous jobs.

\section{Functional disability}

Patient total scores for the ADL scale were in the range $14-40$, with a mean of $18.38 \pm 6.35$. Further, 38 (29.2\%) of the 130 participants had obvious functional disability (Figure 3), while $16(12.3 \%)$ had PSMS disability (Figure 4) and 78 (60.0\%) IADL disability (Figure 5).

\section{Univariable and multivariable analysis-ADL}

Univariable analysis indicated that demographic and clinical risk factors significantly associated with ADL were sex, age, education, ICU admission diagnoses, and APACHE II score (Table 2). In subsequent multiple linear regression analysis, all significant factors identified by univariable analysis were taken as independent variables, with the total ADL score taken as the dependent variable. According to the principle of the least squares method, a final model comprising three independent variables (age, ICU admission diagnosis of acute exacerbation of chronic obstructive pulmonary disease (AECOPD), and APACHE II score) was obtained using a stepwise regression method. The final multiple regression model was statistically significant $(\mathrm{F}=10.080, \mathrm{P}<0.001)$. The variance inflation factor for the three independent variables was $<4$, indicating that there was no collinearity. These three variables explained $33.5 \%$ of the variation in the total ADL score (Table 3).

\section{PTSD}

Patient total scores for the IES-R were in the range 2-49, with mean score $19.58 \pm 11.81$. Of the 130 participants, 23 $(17.7 \%)$ had symptoms consistent with PTSD, likely related to their critical illness, according to IES-R scores $\geq 35$.

\section{Univariable and multivariable analysis-PTSD}

By univariable analysis, demographic and clinical risk factors significantly associated with PTSD were ICU length of stay and hospital length of stay (Table 4). In subsequent multiple linear regression analysis, all significant factors identified by univariable analysis were included as independent variables, with total IES-R score taken as the dependent variable. According to the principle of the least squares method, a final multiple model containing only one independent variable (ICU length of stay) was obtained 
Table 1 Characteristics of patients with or without follow-up data

\begin{tabular}{|c|c|c|c|c|}
\hline Characteristic & Patients with follow-up $(n=130)$ & Patients without follow-up ( $n=118)$ & $\chi^{2}$ & $\mathrm{P}$ \\
\hline Male & $94(72.3)$ & $89(75.4)$ & 0.311 & 0.577 \\
\hline Female & $36(27.7)$ & $29(24.6)$ & & \\
\hline \multicolumn{5}{|l|}{ Age (years) } \\
\hline$\geq 60$ & $72(55.4)$ & $90(76.3)$ & & \\
\hline \multicolumn{5}{|l|}{ Education } \\
\hline Primary school and below & $37(28.5)$ & $48(40.7)$ & 4.243 & 0.120 \\
\hline Junior school & $49(37.7)$ & $39(33.1)$ & & \\
\hline \multicolumn{5}{|l|}{ Admission diagnosis } \\
\hline Severe pneumonia & $30(23.1)$ & $41(34.7)$ & 28.266 & $0.001^{\star *}$ \\
\hline Cardiac surgery & $22(16.9)$ & $3(2.5)$ & & \\
\hline Other surgical & $27(20.8)$ & $15(12.7)$ & & \\
\hline Lung transplantation & $17(13.1)$ & $7(5.9)$ & & \\
\hline AECOPD $^{j}$ & $16(12.3)$ & $18(15.3)$ & & \\
\hline Others & $18(13.8)$ & $34(28.8)$ & & \\
\hline \multicolumn{5}{|l|}{ APACHE II score" } \\
\hline$<15$ & $56(43.1)$ & $45(38.1)$ & 0.969 & 0.623 \\
\hline $8-14$ & $39(30.0)$ & $33(28.0)$ & & \\
\hline$\geq 15$ & $33(25.4)$ & $38(32.2)$ & & \\
\hline \multicolumn{5}{|l|}{ ICU length of stay (days) } \\
\hline $2-7$ & $31(23.8)$ & $33(28.0)$ & 11.544 & $0.003^{\star *}$ \\
\hline $8-14$ & $48(36.9)$ & $21(17.8)$ & & \\
\hline$\geq 15$ & $51(39.2)$ & $64(54.2)$ & & \\
\hline \multicolumn{5}{|l|}{ Hospital length of stay (days) } \\
\hline$\leq 14$ & $8(6.2)$ & $7(5.9)$ & 1.459 & 0.482 \\
\hline $15-28$ & $50(38.5)$ & 37 (31.4) & & \\
\hline$\geq 29$ & $72(55.4)$ & $74(62.7)$ & & \\
\hline
\end{tabular}

Data are presented as $\mathrm{n}(\%)$. Of 248 patients enrolled in the study; 130 patients completed the interview. ${ }^{\S} \mathrm{MV}$, mechanical ventilation; ${ }^{5}$ AECOPD, acute exacerbation of chronic obstructive pulmonary disease; 'APACHE II, acute physiology and chronic health evaluation II. Scores range from 0 to 71 (higher score indicates a worse outcome). ${ }^{* *}, \mathrm{P}<0.01$. 


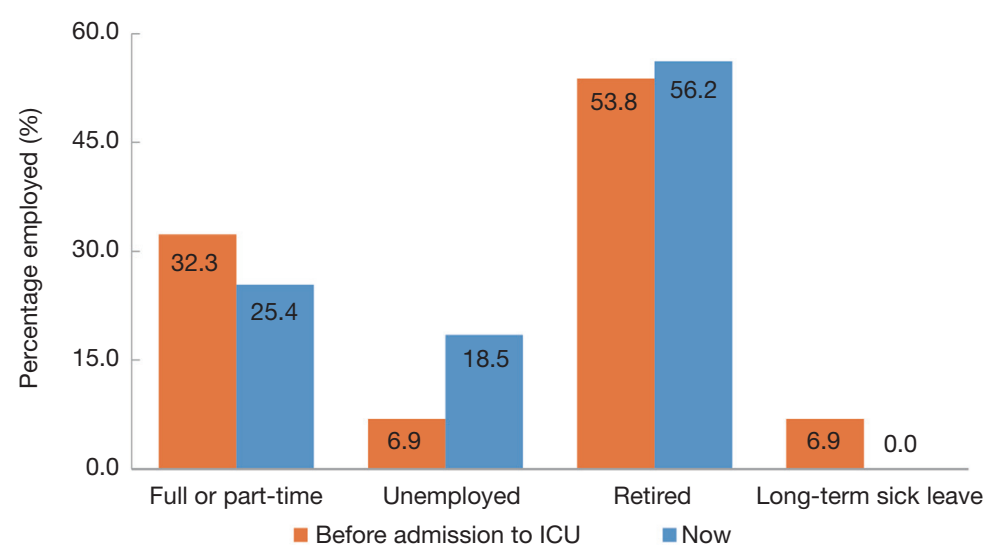

Figure 2 Comparison of employment before and after ICU admission. ICU, intensive care unit.

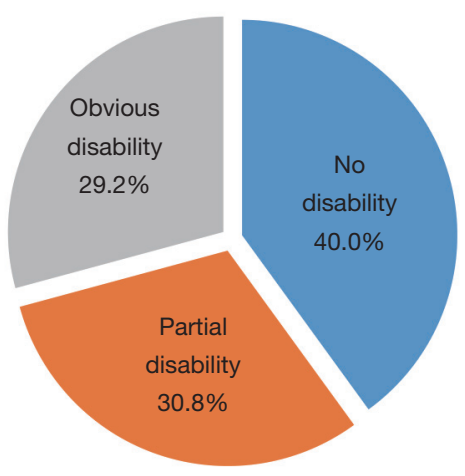

Figure 3 Functional disability prevalence. Pie chart shows the incidence of functional disability according to score on ADL scale. If $\geq 2$ items scored $\geq 3$ points, or the total ADL scale score was $\geq 22$ points, it was considered obvious disability of daily living. ADL, activities of daily living.

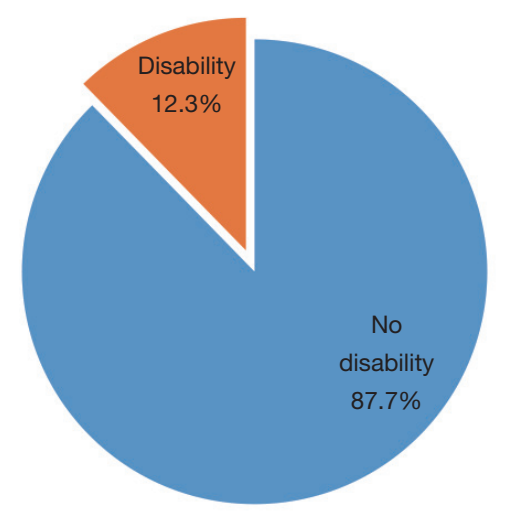

Figure 4 Prevalence of PSMS disability. PSMS, Physical Selfmaintenance Scale.

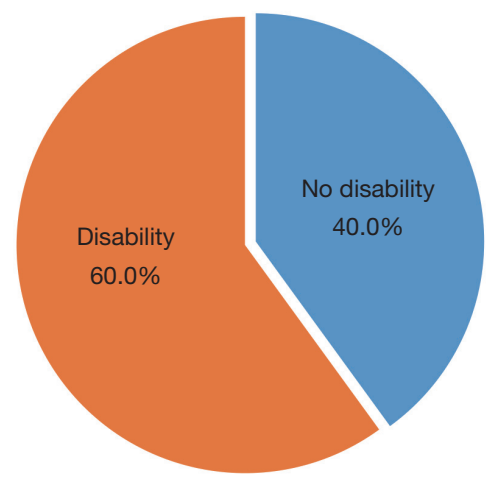

Figure 5 Prevalence of IADL disability. IADL, Instrumental Activity of Daily Living Scale.

by stepwise regression. The final multiple regression model was statistically significant $(\mathrm{F}=11.459, \mathrm{P}<0.001)$ and explained $7.5 \%$ of the variation in IES-R score (Table 5 ).

\section{Discussion}

Our findings suggest the potential long-lasting impact on employment of critical illness and ICU admission. The physical and psychological impairments of survivors might contribute to the negative impact on employment. This observation was consistent with earlier reports $(22,23)$.

Our data support the view that critical illness and ICU experience are gateways to the development of functional deficits. Several studies have reported that muscle weakness and functional deficits due to critical illness can persist for years after ICU discharge (15). The results of the current study are completely consistent with those of earlier 
Table 2 Univariate analysis of activities of daily living scale scores $\left[\mathrm{M}\left(\mathrm{P}_{25}-\mathrm{P}_{75}\right)\right]$

\begin{tabular}{|c|c|c|c|}
\hline Variable & ADL scale & $\mathrm{KW} / \mathrm{Z} / \mathrm{r}$ & $P$ value \\
\hline \multicolumn{4}{|l|}{ Sex } \\
\hline Male & $16.00(14.00-20.75)$ & $-2.303^{\dagger}$ & $0.021^{*}$ \\
\hline Female & $14.00(14.00-17.00)$ & & \\
\hline \multicolumn{4}{|l|}{ Age (years) } \\
\hline$\geq 60$ & $19.00(14.00-22.75)$ & & \\
\hline \multicolumn{4}{|l|}{ Education } \\
\hline Primary school and below & $19.00(14.00-28.00)$ & $11.680^{\dagger}$ & $0.003^{\star \star}$ \\
\hline Junior school & $14.50(14.00-18.75)$ & & \\
\hline \multicolumn{4}{|l|}{ ICU admission diagnosis } \\
\hline Severe pneumonia & $16.00(14.00-21.25)$ & $30.900^{\dagger}$ & $0.001^{\star *}$ \\
\hline Cardiac surgery & $14.00(14.00-17.00)$ & & \\
\hline Other surgical & $14.00(14.00-16.00)$ & & \\
\hline Lung transplantation & $17.00(16.00-19.75)$ & & \\
\hline AECOPD $^{j}$ & $26.00(19.00-36.00)$ & & \\
\hline Others & $15.00(14.00-18.00)$ & & \\
\hline \multicolumn{4}{|l|}{ Length of MV (days) $)^{\S}$} \\
\hline $2-7$ & $15.50(14.00-19.00)$ & $4.326^{\dagger}$ & 0.115 \\
\hline \multicolumn{4}{|l|}{ ICU length of stay (days) } \\
\hline$\geq 15$ & $16.00(14.00-21.00)$ & & \\
\hline \multicolumn{4}{|l|}{ Hospital length of stay (days) } \\
\hline$\leq 14$ & $16.50(14.00-19.75)$ & $0.071^{\dagger}$ & 0.965 \\
\hline $15-28$ & $15.50(14.00-21.00)$ & & \\
\hline$\geq 29$ & $16.00(14.00-19.00)$ & & \\
\hline APACHE II & & $0.211^{\ddagger}$ & $0.017^{*}$ \\
\hline
\end{tabular}

${ }^{\dagger}$, KW or Z value-independent sample rank sum tests (Kruskal-Wallis $\mathrm{H}$ ); ${ }^{\ddagger}, \mathrm{r}$ value-Spearman's rank correlation coefficient [correlation analysis of APACHE II (non-normally distributed data) and ADL]; ${ }^{\S} \mathrm{MV}$, mechanical ventilation; ' $\mathrm{AECOPD}$, acute exacerbation of chronic obstructive pulmonary disease; 'APACHE II, acute physiology and chronic health evaluation II; ${ }^{*}, \mathrm{P}<0.05 ;{ }^{* \star}, \mathrm{P}<0.01$. 
Table 3 Multiple linear regression analysis of activities of daily living scale scores

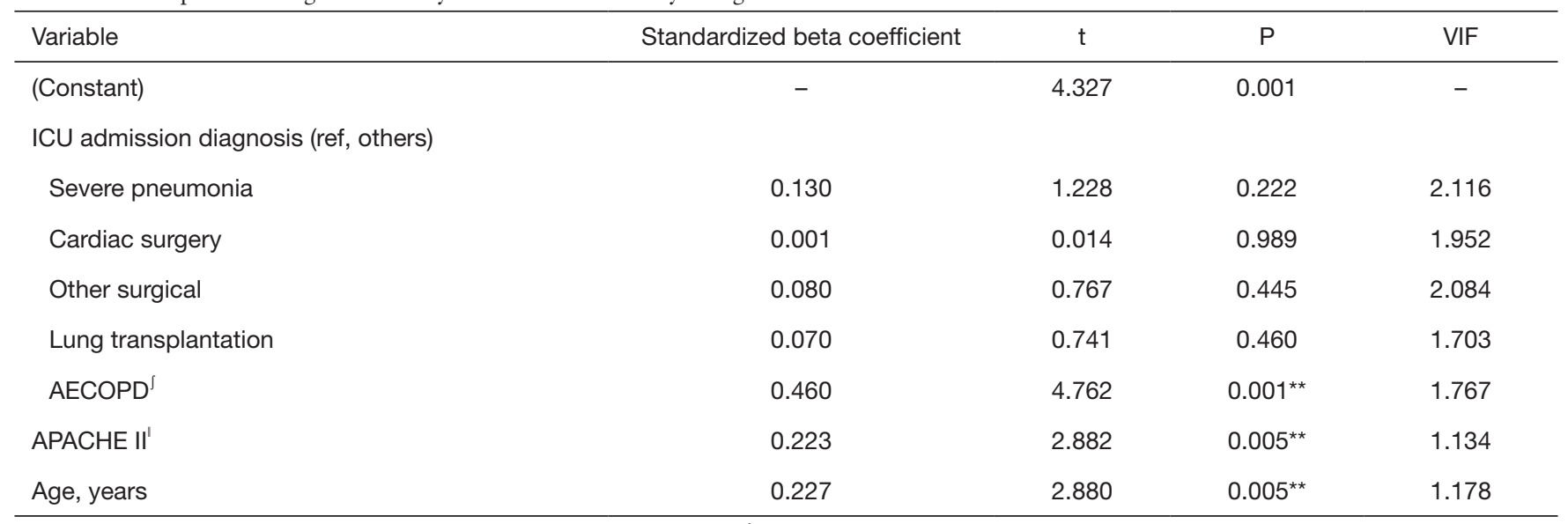

$\mathrm{F}=10.080, \mathrm{P}<0.001, \mathrm{R}$ square $=0.372$, adjusted $\mathrm{R}$ square $=0.335 .{ }^{\top} \mathrm{AECOPD}$, acute exacerbation of chronic obstructive pulmonary disease;

'APACHE II, acute physiology and chronic health evaluation II; **, $\mathrm{P}<0.01$.

investigations. We found that almost a third of survivors had ADL scale scores suggesting a significant impairment of ADL. Further analysis showed that $12.3 \%$ of survivors had impaired physical self-maintenance and $60 \%$ had impaired instrumental ADL at an average of 19.64 months after ICU discharge. Early studies reported that disabilities in basic ADL were present in $27 \%$ patients, with disabilities in instrumental $\mathrm{ADL}$ in $23 \%$ of individuals at 12 months (2). The varying rates of morbidity may be explained by differences in inclusion criteria for research subjects, evaluation instruments, and timing of assessments.

Deficiency of physical self-maintenance, recorded as deficits in PSMS, has been widely studied in ICU survivors; however, instrumental ADL has not been extensively explored (24). In this study, we were interested in evaluating deficits in instrumental ADL, which we found to exhibit higher levels of morbidity than those of physical selfmaintenance. These results suggest that the deficits in ADL are mainly characterized by impairments in instrumental ADL. Physical self-maintenance and instrumental ability of daily living are two aspects of ADL. One is the most basic ability of an individual to complete physical activities, while the other is the basic ability to carry out social activities; the two are closely related, but also differ in some ways. If an individual's ability for physical self-maintenance is impaired, their instrumental ADL will also be impaired. In contrast, if an individual's instrumental ADL is impaired, their physical self-maintenance ability may be normal, while their ability to live independently remains affected. This may be one of the reasons for the higher morbidity observed related to deficits in instrumental ADL.

The variables, ICU admission diagnosis of acute exacerbation of chronic obstructive pulmonary disease (AECOPD), APACHE II score, and age were identified as major predictors of ADL in this study, and could explain $33.5 \%$ of variance in ADL. Compared with other admission diagnoses, ICU survivors of AECOPD had poorer $\mathrm{ADL}$, which may be related to the disease characteristics of COPD. Patients with COPD are characterized by activity intolerance and limited daily activities, due to dyspnea, fatigue, decreased muscle strength, and especially respiratory distress, which appears on, or aggravates during, physical activity. These results also demonstrate that ICU survivors with higher scores for APACHE II were more liable to have deficits in ADL. APACHE II is a severity score and mortality estimation tool developed from a large sample of ICU patients in the United States (18). Higher scores for APACHE II indicate worse patient condition on admission to ICU and such patients often need longer mechanical ventilation, and an extended recovery period. A few studies have consistently reported that older individuals were more likely to have a poorer $\operatorname{ADL}(2,25)$. As we get older, body tissues and organs age, physiological resistance declines, and the prevalence of various chronic diseases gradually increases, leading to reduced physical function and impaired ADL.

Our investigation suggests that critical illness can be a gateway to development of mental health impairments. PTSD, an important mental health condition related to critical illness and ICU experiences, mainly manifests as the 
Table 4 Univariate analysis of Impact of Event Scale-Revised scores $\left[\mathrm{M}\left(\mathrm{P}_{25}-\mathrm{P}_{75}\right)\right]$

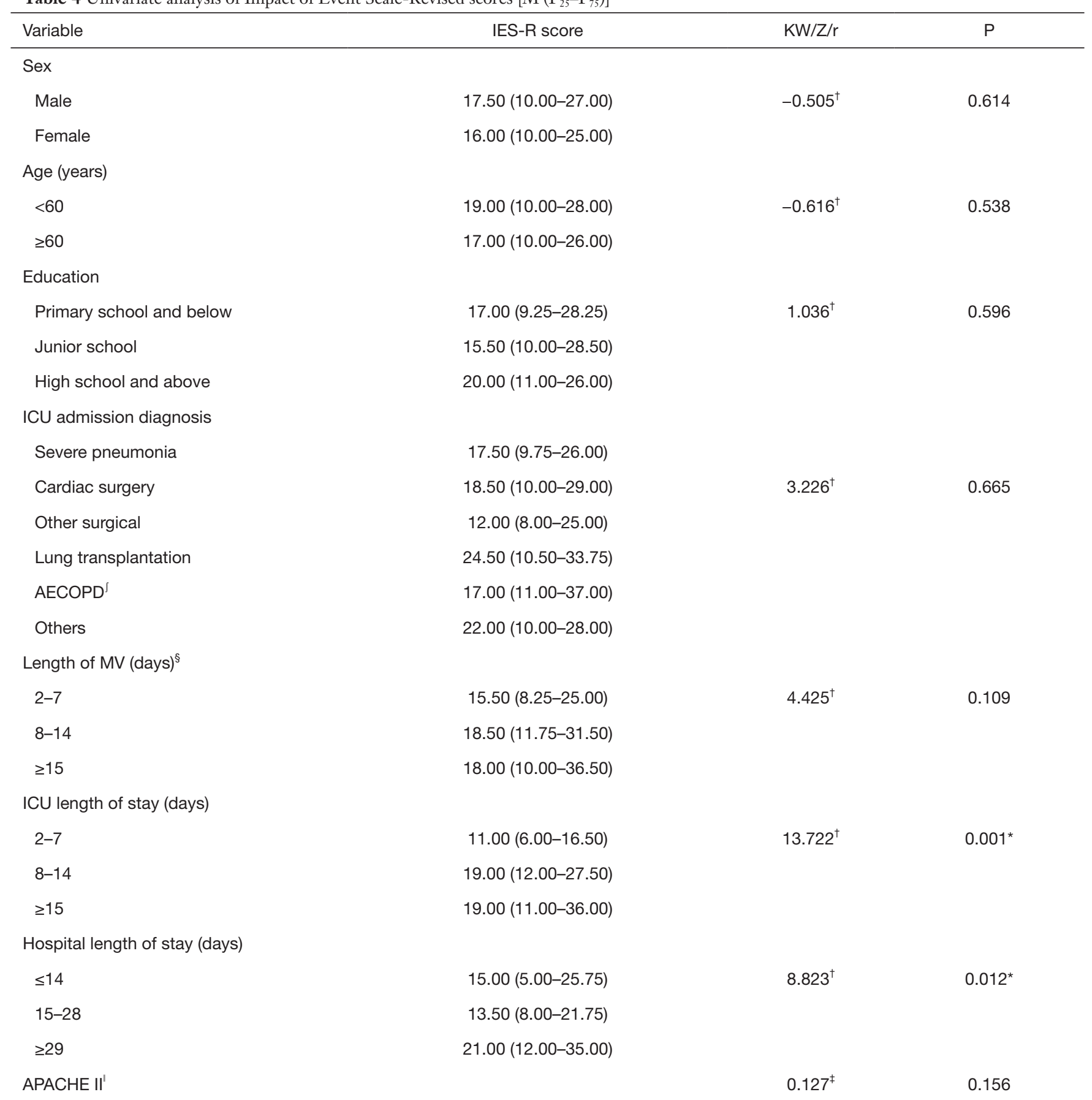

${ }^{\dagger}$, KW or Z value-independent sample rank sum tests (Kruskal-Wallis $\mathrm{H}$ ); ${ }^{\ddagger}, \mathrm{r}$ value-Spearman's rank correlation coefficient [correlation analysis of APACHE II (non-normally distributed data) and IES-R]; ${ }^{\S} \mathrm{MV}$, mechanical ventilation; ${ }^{\dagger} \mathrm{AECOPD}$, acute exacerbation of chronic obstructive pulmonary disease; 'APACHE II, acute physiology and chronic health evaluation II; ${ }^{*}, \mathrm{P}<0.05$. 
Table 5 Multiple linear regression analysis of Impact of Event Scale-Revised scores

\begin{tabular}{lcccc}
\hline Variable & Standardized beta coefficient & $t$ & $P$ & VIF \\
\hline (Constant) & - & 3.504 & 0.001 & - \\
ICU length of stay (days) & 0.287 & 3.385 & $0.001^{* *}$ & 1.000 \\
\hline
\end{tabular}

$\mathrm{F}=11.459, \mathrm{P}<0.001, \mathrm{R}$ squared $=0.082$, adjusted $\mathrm{R}$ squared $=0.075{ }^{* \star}, \mathrm{P}<0.01$.

following symptoms: persistent re-experiencing of the event and attempting to avoid stimuli; new negative alterations in mood or cognition; and new or increased arousal $(26,27)$. Early studies reported that clinically important PTSD symptoms occurred in 7-24\% of ICU survivors $(2,27,28)$. We noted a $17.7 \%$ rate of symptoms of PTSD, which is consistent with earlier studies, and suggests that, despite a long period of recovery, the traumatic events of experiencing critical illness and ICU treatment continue to impact on the lives of survivors.

In this investigation, high levels of PTSD symptoms were most likely to occur in patients with a longer length of ICU stay. A recent large population-based cohort study found that ICU survivors exposed to longer ICU stays might be at higher risk of subsequent mental illnesses (adjusted hazard ratio 1.004 per additional day, 95\% confidence interval 1.003-1.005) (5). A study by Rattray et al. (29) also showed that higher intrusion (one of the core features of post-traumatic stress) scores were associated with a longer intensive care stay. Given that ICU survivors have poor recall for factual events of intensive care, it may be that memories which are processed without apparent recall return later as intrusive thoughts (29); in particular, the recall of delusional memories of ICU experience was found to be related to the development of PTSD (28).

Our results complement previous studies that exposed the long-term outcomes in ICU survivors. However, some differences exist between our investigation and earlier studies. First, this was the first local study to assess the functional disability and PTSD in survivors of mechanical ventilation. Second, since instrumental ADL hasn't been extensively explored, we collected data about instrumental $\mathrm{ADL}$ and analyzed the risk factors of ADL.

\section{Limitations of the study}

The current study also has several limitations. First, this was a cross-sectional study; hence, causality between variables cannot be inferred from the results. Longitudinal studies with longer study periods will be more interesting and valuable. Second, the sample size and single-center nature of the investigation may limit the generalization of our conclusions. Third, we excluded individuals with preexisting mental health illnesses and obvious deficits of ADL by asking health-care proxies. This subjective approach could have led to an underestimation of premorbid mental illnesses and physical impairments; however, as for similar studies, it was difficult to assess the condition of subjects before ICU admission, due to the unplanned nature of critical illness. Finally, direct observation was not possible, thus we relied on self-reported investigation by telephone; hence, recall bias or social desirability bias may have influenced our findings.

\section{Conclusions}

The current study is one few follow-up studies on the long-term social, physiological, and psychological status of patients who undergo mechanical ventilation after intensive care in mainland China. The results enrich the information base relating to the long-term prognosis of ICU survivors and demonstrate that many survivors of mechanical ventilation may face changes in their employment, and have significant functional disabilities and PTSD symptoms. Strikingly, only ICU length of stay was correlated with PTSD, and further studies to confirm these results are needed. Our results lend weight to limited existing evidence that ICU admission, age, and APACHE II score are linked to ADL after intensive care. These findings suggest that some ICU survivors with certain exposures may warrant closer follow-up, and systematic interventions for these high-risk survivors in China may be justified. This study provides a preliminary theoretical basis for the rehabilitation of patients who experience severe consequences following a period in ICU and the optimal allocation of medical and health resources.

\section{Acknowledgments}

We especially acknowledge the medical staff in The 1st 
Affiliated Hospital of Guangzhou Medical University. We also thank the patients for their willingness to participate in the research.

Funding: The research was supported by National Science and Technology Major project (No. 2017ZX10204401).

\section{Footnote}

Reporting Checklist: The authors have completed the STROBE reporting checklist. Available at http://dx.doi. org/10.21037/jtd-20-2622

Data Sharing Statement: Available at http://dx.doi. org/10.21037/jtd-20-2622

Conflicts of Interest: All authors have completed the ICMJE uniform disclosure form (available at http://dx.doi. org/10.21037/jtd-20-2622). The authors have no conflicts of interest to declare.

Ethical Statement: The authors are accountable for all aspects of the work in ensuring that questions related to the accuracy or integrity of any part of the work are appropriately investigated and resolved. The study was conducted in accordance with the Declaration of Helsinki (as revised in 2013). The study was approved by Ethical Committee of Guangzhou Medical University (No.: 201749) and informed consent was taken from all the patients.

Open Access Statement: This is an Open Access article distributed in accordance with the Creative Commons Attribution-NonCommercial-NoDerivs 4.0 International License (CC BY-NC-ND 4.0), which permits the noncommercial replication and distribution of the article with the strict proviso that no changes or edits are made and the original work is properly cited (including links to both the formal publication through the relevant DOI and the license). See: https://creativecommons.org/licenses/by-nc-nd/4.0/.

\section{References}

1. Wu JF, Pei F, Ouyang B, et al. Critical care resources in Guangdong province of China: Three surveys from 2005 to 2015. Crit Care Med 2017;45:e1218-25.

2. Jackson JC, Pandharipande PP, Girard TD, et al. Depression, post-traumatic stress disorder, and functional disability in survivors of critical illness in the BRAIN-ICU study: A longitudinal cohort study. Lancet Respir Med 2014;2:369-79.

3. Needham DM, Davidson J, Cohen H, et al. Improving long-term outcomes after discharge from intensive care unit: Report from a stakeholders' conference. Crit Care Med 2012;40:502-9.

4. Elliott D, Davidson JE, Harvey MA, et al. Exploring the scope of post-intensive care syndrome therapy and care: Engagement of non-critical care providers and survivors in a second stakeholders meeting. Crit Care Med 2014;42:2518-26.

5. Sivanathan L, Wunsch H, Vigod S, et al. Mental illness after admission to an intensive care unit. Intensive Care Med 2019;45:1550-8.

6. Bastian K, Hollinger A, Mebazaa A, et al. Association of social deprivation with 1-year outcome of ICU survivors: results from the FROG-ICU study. Intensive Care Med 2018;44:2025-37.

7. Righy C, Rosa RG. Prevalence of post-traumatic stress disorder symptoms in adult critical care survivors: A systematic review and meta-analysis. Crit Care 2019;23:213.

8. Bienvenu OJ, Friedman LA, Colantuoni E, et al. Psychiatric symptoms after acute respiratory distress syndrome: A 5-year longitudinal study. Intensive Care Med 2018;44:38-47.

9. Desai SV, Law TJ, Needham DM. Long-term complications of critical care. Crit Care Med 2011;39:371-9.

10. Brummel NE, Balas MC, Morandi A, et al. Understanding and reducing disability in older adults following critical illness. Crit Care Med 2015;43:1265-75.

11. Wintermann GB, Brunkhorst FM, Petrowski K, et al. Stress disorders following prolonged critical illness in survivors of severe sepsis. Crit Care Med 2015;43:1213-22.

12. Bein T, Bienvenu OJ, Hopkins RO. Focus on long-term cognitive, psychological and physical impairments after critical illness. Intensive Care Med 2019;45:1466-8.

13. Riddersholm S, Christensen S, Kragholm K, et al. Organ support therapy in the intensive care unit and return to work: A nationwide, register-based cohort study. Intensive Care Med 2018;44:418-27.

14. Herridge MS, Cheung AM, Tansey CM, et al. One-year outcomes in survivors of the acute respiratory distress syndrome. N Engl J Med 2003;348:683-93.

15. Herridge MS, Tansey CM, Matte A, et al. Functional disability 5 years after acute respiratory distress syndrome. N Engl J Med 2011;364:1293-304.

16. Hair JF, Anderson RE. Multivariate Data Analysis. New 
Jersey: Prentice Hall, 1998.

17. Li R, Zhang H, Chen L, et al. Long-term outcomes of survivors of mechanical ventilation in intensive care unit (ICU) and their views on ICU rehabilitation clinics. Zhonghua Wei Zhong Bing Ji Jiu Yi Xue 2020;32:1008-12.

18. Knaus WA, Draper EA, Wagner DP, et al. APACHE II: A severity of disease classification system. Crit Care Med 1985;13:818-29.

19. Lawton MP, Brody EM. Assessment of older people: Selfmaintaining and instrumental activities of daily living. Gerontologist 1969;9:179-86.

20. Weiss D, Marmer C. The impact of event scale-revised. In: Wilson J, Keane T. editors. Assessing psychological trauma and PTSD: A practitioner's handbook. New York: Guilford Press, 1996:399-411.

21. Maercker A, Schützwohl M. Impact of event scale revidierte form. In: Brähler E, Schumacher J, Strauß B. editors. Diagnostische Verfahren in der Psychotherapie. Göttingen: Hogrefe, 2002:176-9.

22. Griffiths J, Hatch RA, Bishop J, et al. An exploration of social and economic outcome and associated health-related quality of life after critical illness in general intensive care unit survivors: A 12-month follow-up study. Crit Care 2013;17:R100.

Cite this article as: Li R, Zhou Y, Liu X, Huang J, Chen L, Zhang H, Li Y. Functional disability and post-traumatic stress disorder in survivors of mechanical ventilation: a cross-sectional study in Guangzhou, China. J Thorac Dis 2021;13(3):1564-1575. doi: $10.21037 /$ jtd-20-2622
23. Kamdar BB, Huang M. Joblessness and lost earnings after acute respiratory distress syndrome in a 1-year national multicenter study. Am J Respir Crit Care Med 2017;196:1012-20.

24. Li B. The present status and influencing factors of postintensive care syndrome in adult after cardiac surgery. MD. Shandong University, 2018.

25. Malembaka EB, Karemere H, Balaluka GB, et al. A new look at population health through the lenses of cognitive, functional and social disability clustering in eastern DR Congo: A community-based cross-sectional study. BMC Public Health 2019;19:93.

26. Wang X, Li L. Post-traumatic stress disorder. Peking: Peking University Medical Press, 2012.

27. Parker AM, Sricharoenchai T, Raparla S, et al. Posttraumatic stress disorder in critical illness survivors: A metaanalysis. Crit Care Med 2015;43:1121-9.

28. Jones C, Bäckman C, Capuzzo M, et al. Precipitants of post-traumatic stress disorder following intensive care: A hypothesis generating study of diversity in care. Intensive Care Med 2007;33:978-85.

29. Rattray JE, Johnston M, Wildsmith JA. Predictors of emotional outcomes of intensive care. Anaesthesia 2005;60:1085-92. 